\title{
Human SYSTEM SAFETY MANAGEMENT AND ENVIRONMENTAL MANAGEMENT RELATION
}

\author{
PRochazKova, D.; WeSSELY, E.; \\ RUSKO, M. \& KRALIKOVA, R.
}

Abstract: Security situation in the world, in each territory and generally in each asset continuously changes with time, and therefore, there is formed new safety culture that takes into account actual knowledge and experiences with interdependences among the public assets leading to extreme social crises. With regard to the historical development at present there are a lot of management types that differ by aims and by assets that they respect. Consecutively in present human society there are groups that shielded by individual management type aims fight against each other, and at the same time all of them goes on only good human existence. The paper deals with the relation between human system safety management and environmental management.

Key words: security, safety, human system, environment, management
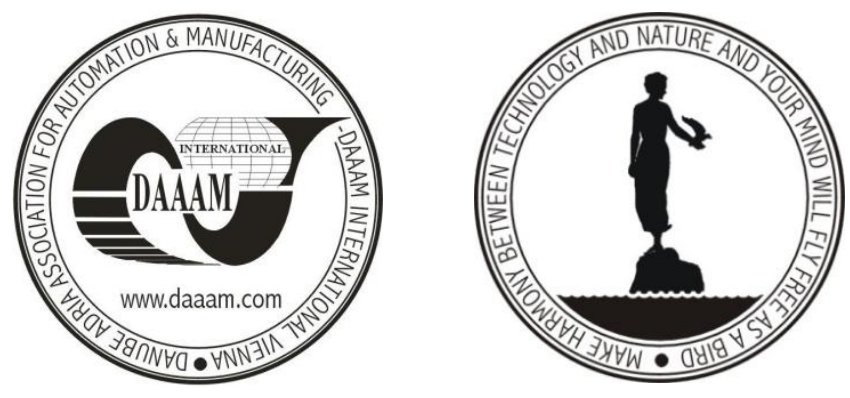

Authors' data: Assoc. Prof. RNDr. Dr.Sc, Prochazkova, D[ana]*; Assoc. Prof. CSc. Wessely, E[mil]**; RNDr., PhD. Rusko, M[iroslav]***; Assoc. Prof. CSc. Kralikova, R[uzena] ${ }^{* * * *}$; *Czech Technical University in Prague, **University of Security Management in Košice, Slovakia, ***Faculty of Technology STU Trnava, Slovakia, ****Technical University of Kosice, Slovakia, emil.wessely@vsbm.sk, ruzena.kralikova@tuke.sk,

This Publication has to be referred as: Prochazkova, D[ana]; Wessely, E[mil]; Rusko, M[iroslav] \& Kralikova, R[uzena] (2011). Human System Safety Management and Environmental Management Relation, Chapter 09 in DAAAM International Scientific Book 2011, pp. 103-118, B. Katalinic (Ed.), Published by DAAAM International, ISBN 978-3-901509-84-1, ISSN 1726-9687, Vienna, Austria DOI: $10.2507 /$ daaam.scibook.2011.09 


\section{Introduction}

Present goal of humans is to live at safe space. In agreement with the EU and $\mathrm{UN}$ proclamations, the professional knowledge and experience there is necessary for conservation and sustainable development of the human society to create the safe territory, safe community, safe state, safe Europe and safe world. The safe space undoubtedly includes the quality environment on which the human lives are strongly dependent. The paper deals with the relation between human system safety management and environmental management (in the sense of above given fact it goes on environmental system safety management but in the most professional sources the word "safety" is not given, and therefore, we respect it).

\section{Human safety management process model}

For investigation purposes the safe space is represented by safe open dynamically variable system that we denote in agreement with the UN report from 1994 (UN,1994) as the Human System. The environment is also the system and from the general view we can say that the environmental system is understood as biosphere elements which include the atmosphere, the hydrosphere, the lithosphere and the ecosphere, the set of interactions among these elements that are caused by links and flows among elements (Raven \& Berg \& Johnson, 1998). In detail both systems are system of systems (SoS), i.e. several overlapping systems. Each system safety is disturbed by disasters, i.e. internal or external phenomena that lead or can lead to damages, harms and losses on system assets and on system oneself. The sources of some disasters are also inherently connected with human lives and activities (Procházková (b), 2011). It means that both systems under account (the environmental system and the human system) are affected by both, the processes, actions and phenomena that are under way in human society, environment, planet system, galaxy and other higher systems, and the human management acts.

\subsection{Base terms of system safety management}

The basic terms of each system safety management are:

- Security is a state of system at which the occurrence of harm or loss on system assets has an acceptable probability (it is almost sure that harm and loss do not origin). To this there is also belonged a certain stability of system in time and space, i.e. a sustainable development in time and space

- Safety is a set of human measures and activities for ensuring the security and sustainable development of system and its assets (protected interests)

- Secure system is a system that is protected against to internal and external disasters

- Safe system is a system that is protected against to internal and external disasters and it does not threated vicinity

- Safe environment is an environment which is secure and it can sustainable develop

- Safe human system represented by safe territory including the human society is a human system the assets of which are public assets marked in Figure 1 are in 
security and they can sustainable develop. Similarly safe organisation is the organisation the assets of which are in security and they can sustainable developed; the organisation assets are public assets and specific assets directly connected with organisation existence

- Human system safety management is the management of human system directed to human system safety the product of which is security and sustainable development of all public assets denoted in Figure 1 .

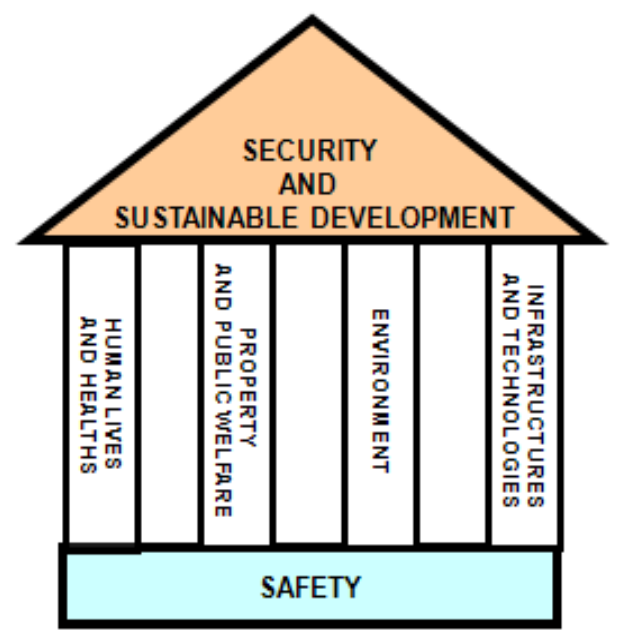

Fig. 1. Human system safety management process model and its public assets (Procházková (b), 2011)

By analogy, the environmental system safety management denoted in main professional sources only as an environmental management is realised by an Environmental Management System (EMS). It refers to the management of an organization's environmental programs in a comprehensive, systematic, planned and documented manner. It includes the organisational structure, planning and resources for developing, implementing and maintaining policy for environmental protection. According to rules given in materials presented in www.epa.gov.ems/, www.inem.org, it:

- serves as a tool to improve environmental performance

- provides a systematic way of managing an subject's environmental affairs

- is the aspect of the subject's overall management structure that addresses immediate and long-term impacts of its products, services and processes on the environment

- gives order and consistency for organizations to address environmental concerns through the allocation of resources, assignment of responsibility and on-going evaluation of practices, procedures and processes

- focuses on continual improvement of the system.

It means that it deals with an organisation or territory safety management with the asset "environment".

Enthusiasm that was in developed countries in the middle of last century, when humans believed that the human kind would have power over disasters (wind, rain, earthquake etc.), was replaced step by step during the time by respect to the Earth's Planet System. At present the human actions and management are implemented by a 
pragmatic approach based on evaluation of credible and relevant data and the humans take into account that their knowledge and capabilities are:

- too small to prevent the origination of disasters that are the manifestation of the Earth's Planet System development

- adequate to mitigate the impacts of disasters that are the manifestation of the Earth's Planet System development

- sufficient to prevent the origination of disasters that are connected with the human actions and with development of human society (so called man-made).

Generally, there is known if we want to control some phenomenon or to avert it, we must know its cause, size, repeat and nature of impact effects on assets. The disaster sizes, namely extreme ones have basic importance for system safety. From them it is unreeled the created protection system, i.e. the system of measures and activities for averting or mitigating the disasters and/or their impacts (Procházková (b), 2011).

There is necessary to take into account that disasters from the viewpoint of the Planet or environment development might be inventive changes supporting these system states and that human with his/her wishes and management goes against them. If it is reasonable and profitable for human in near or distant future, we cannot estimate because our fittings in this domain are very poor and such question has been only recently appeared in professional domain. Therefore, there is necessary to use the precaution principle in each system management. This principle is inherently included in safety management that denotes strategic management ensuring the identification, diagnose, enforcement and implementation (EU, 2000). According to present knowledge the processes induced the disasters in both considered systems are denoted in Figure 2.

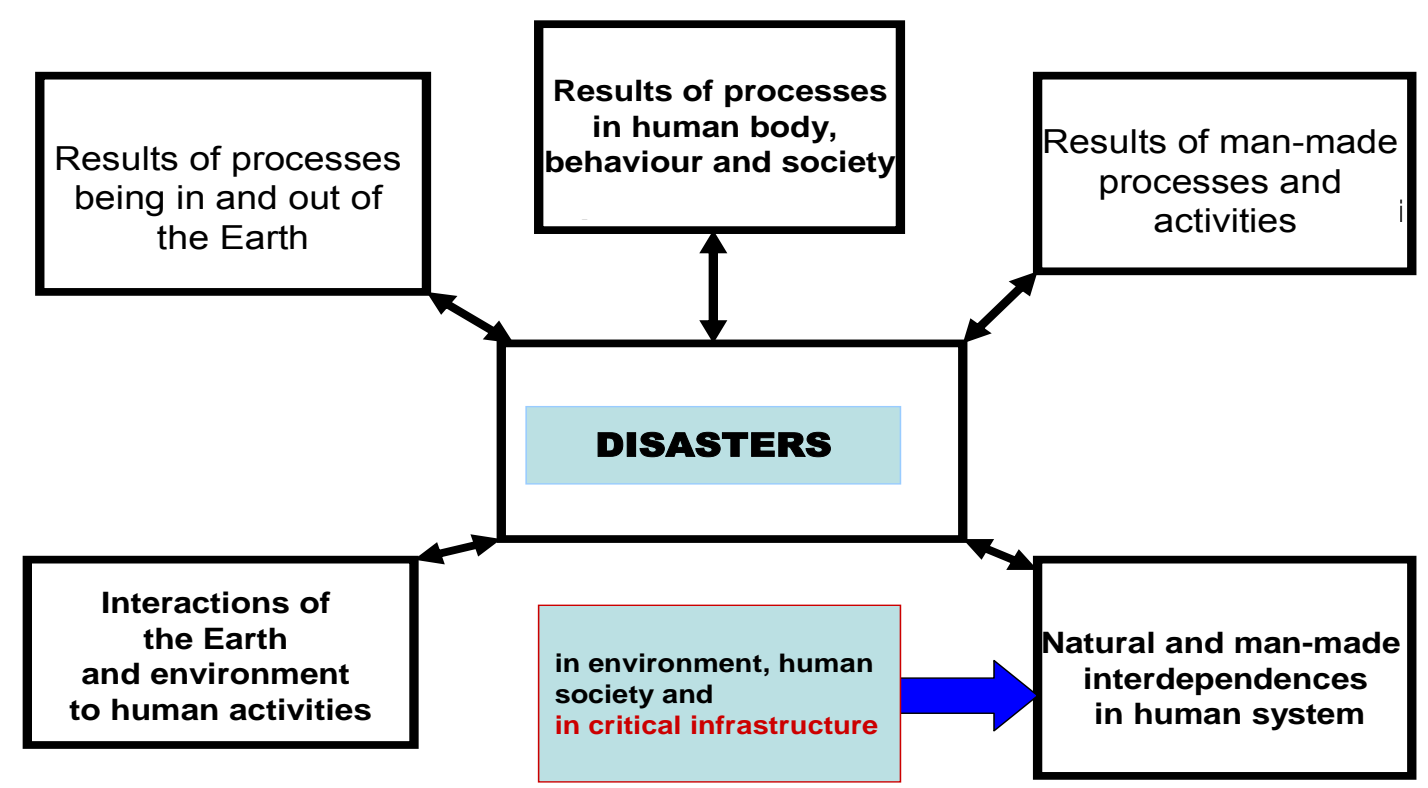

Fig. 2. Sources of disasters in the system of human and environment

At the disaster occurrence there are originated chains of undesirable phenomena (impacts, consequences) of external and internal character, primary and secondary, which affect negatively system assets in different intensities and in different time moments. The substantial role plays the local vulnerability and 
pertinent faults in human behaviour or management on all levels. The disasters are the cause of emergency situations, the severity of which substantially increases if cascade impacts occur, Figure 3.

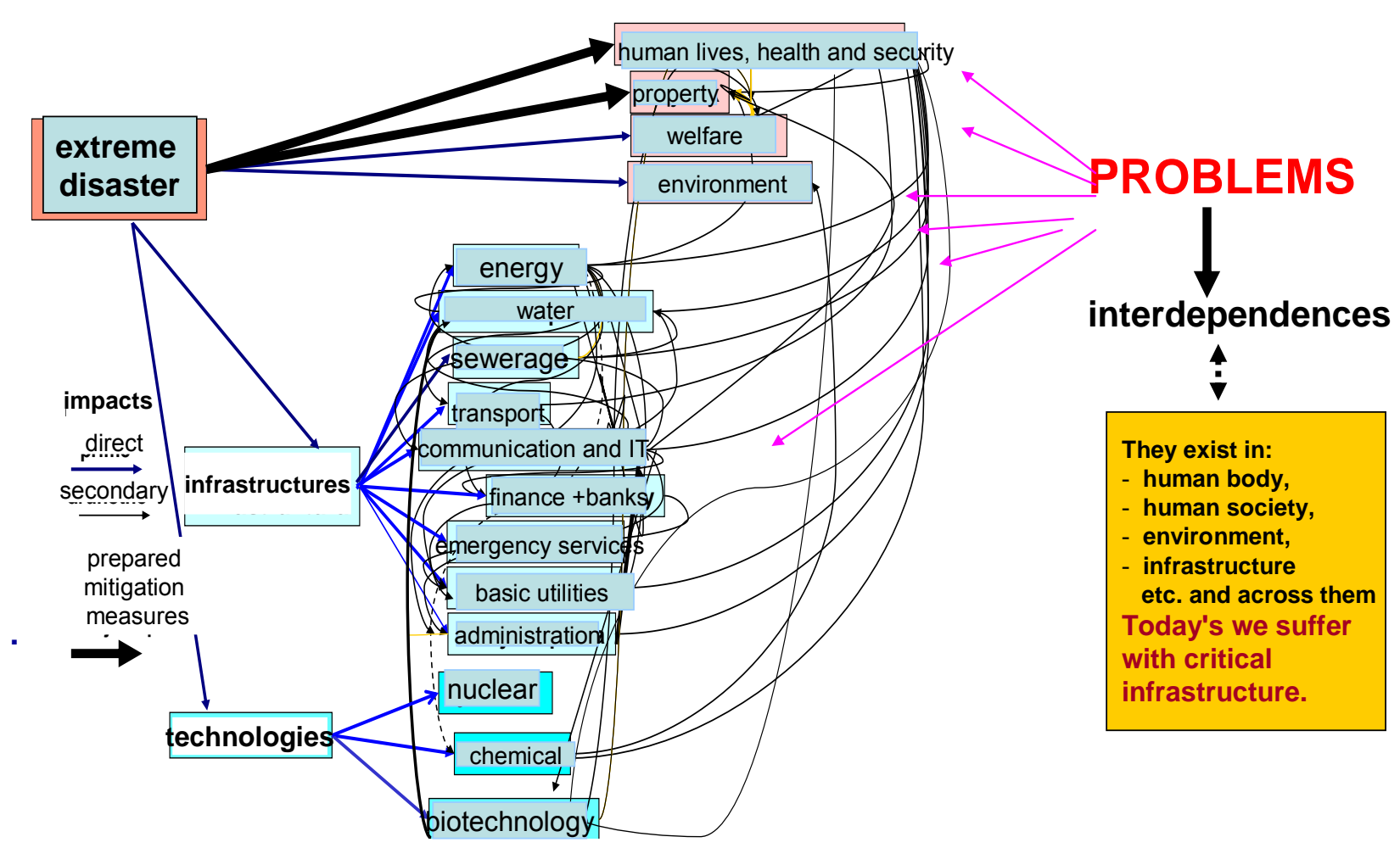

Fig. 3. The extreme disaster impacts (Procházková (b), 2011)

\subsection{The roles of systems safety management}

Regarding to present knowledge and experience each system safety management must arrange to:

- precede disasters if possible, e.g. in case of natural disasters it is impossible

- eliminate the causes of severe disaster impacts or at least to reduce their occurrence frequency

- mitigate unacceptable disaster impacts by preventive measures, preparedness, optimal defeating the disaster impacts and by them defeating the induced critical situations (i.e. really the reducing the emergency duration to acceptable amount), ensure renovation and start of further development of system considered.

It holds for both, the human system safety management (Procházková (b), 2011) and for environmental management (www.epa.gov.ems/, www.inem.org). From the present knowledge viewpoint there is necessary to ensure in order that each system management directed to safety might be proactive, strategic and might consider facts, findings, experiences and their correct evaluation. The reactive management is only admissible on operative level when emergency or critical situations have been occurred, i.e. in times when there is necessary to solve problems immediately and when no time for deep analysis and assessments that are challenging for data, methods and processing time (US, 2004). Therefore, in practice we realise third level safety management, Figure 4. 


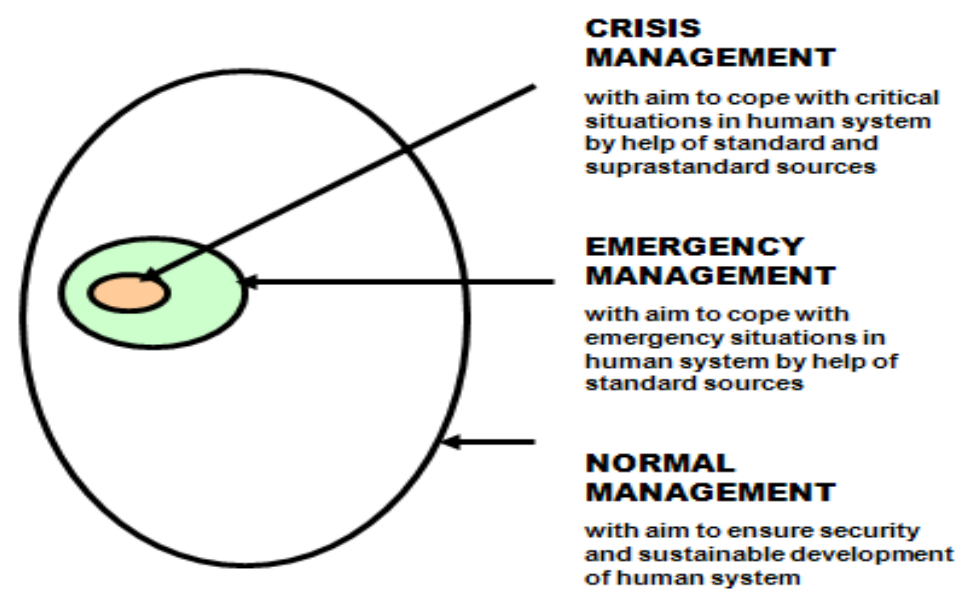

Fig. 4. The safety management levels (Procházková (b), 2011)

\section{Risk and safety management principles}

Strategy of management for ensuring the security and sustainable development of managed subject consists in negotiation with risks (OECD, 2006). According to present possibilities of human society we apply several ways of negotiation with risk:

- part of risk is reduced, i.e. by preventive measures the risk realisation is averted

- part of risk is mitigated, i.e. by preventive measures and by preparedness (warning systems and another measures of emergency and crisis management) there are reduced or averted non-acceptable impacts

- part of risk is re-insured

- part of risk for which response and renovation will be necessary there are prepared resources for response and renovation

- part of risk for which there is only prepared contingency plan, i.e. this part of risk is non-controllable, too expensive or low frequent.

To this it is joined the distribution of risk defeating among all stakeholders (Procházková (a), 2011). The distribution in good governance is performed according to rule that all stakeholders have responsibility for risk defeat and that the defeat of real risk is assigned to a subject the preparedness of which is the best.

For risk management there are used two models:

- classical risk management, see Figure 5.

- safety management, i.e. risk governance for security and sustainable development, see Figure 6.

Figure 6 shows model of safety assessment in territory $\mathrm{RRD}_{(\mathrm{i})}$ (risk from the ith relevant disaster. It illustrates that if we find that the safety level is unacceptable, the assessment process must return to level of integral residual risk. The residual risks from individual relevant disasters $\left(\mathrm{RRD}_{(1)}, \mathrm{RRD}_{(2)}, \ldots \mathrm{RRD}_{(\mathrm{n})}\right)$ must be once again judged and they must be revealed the causes of these residual risks. First and foremost, it is surveyed if the source of high integral risk could not have been performed by measures for reduction of risks from some of disasters that were taken into account. 


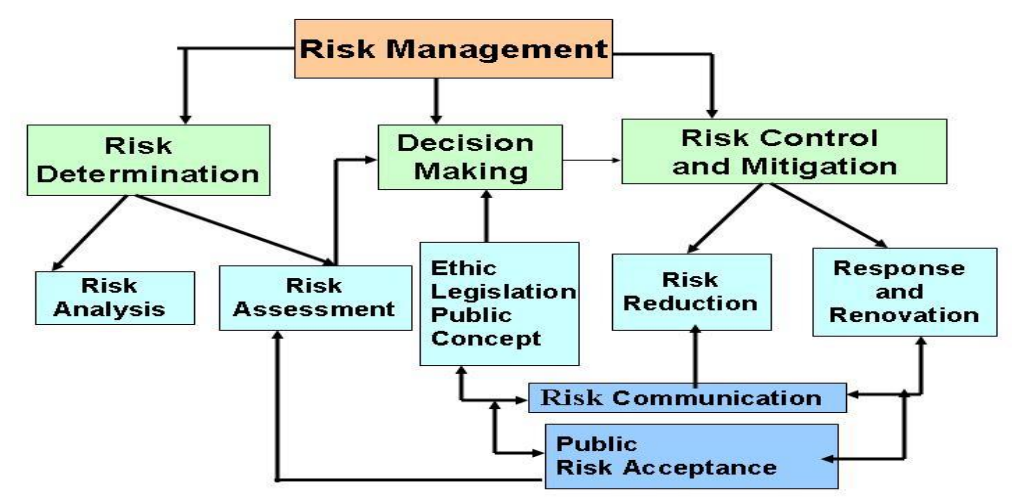

Fig. 5. Model of risk management of subject under account
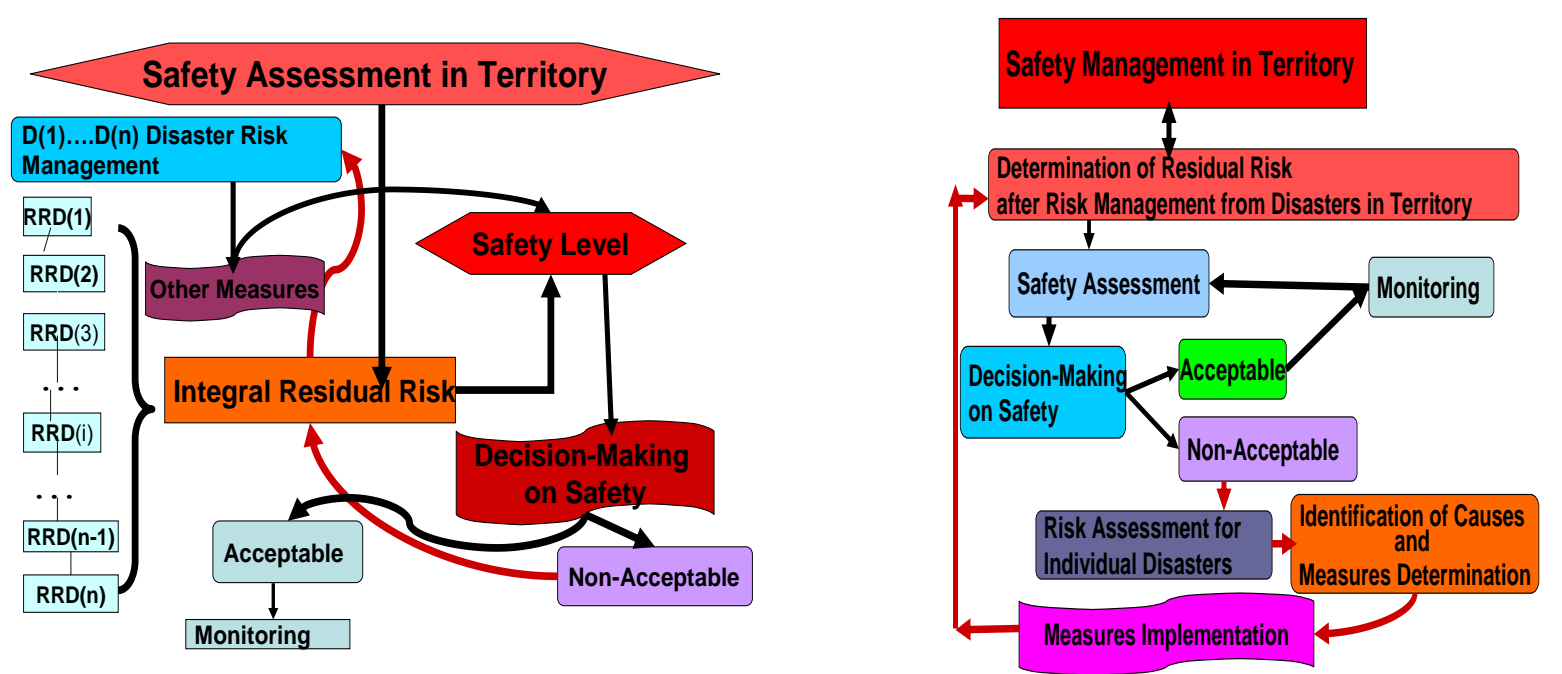

Fig. 6. Model of safety assessment in territory RRD(i)

Because the safety is changed in time scale, the safety assessment cycle must repeat in time. From Figure 6 it is clear that safety management of subject under account leans on safety assessment, safety monitoring, and risk management from individual disasters and on considering the lings among the corrective measures for reducing the real risks from disasters in system containing all relevant disasters for subject.

For classical / standard risk management and for risk governance in subject it is necessary:

- To understand the process of disaster origination and the conditions under which the process goes on

- To know the sites in which the disaster can originate and its probable physical and other characteristics

- To identify the hazard that disaster means for a given subject according to stipulated rules

- To determine the impacts of disaster with size equals to a hazard on assets.

- To eliminate the unacceptable disaster impacts in cases in which it is possible with acceptable expenses

- For residual impacts to calculate by help of predictive models their occurrence probability respecting the fact that there are also considered possible failures of preventive measures 
- To calculate possible harms of assets in considered subject with regard to assets, that are really in the subject considered and by help of occurrence probability to determine the risk size

- To identify and to realize the mitigation measures with regard to considered assets in the way that they may be ALARP (as low as reasonably practicable)

- To prove that all measures for averting and mitigating the risks were performed.

The acceptable risk can be achieved by hazard reduction of disasters, which are only connected with human activities, and above all by reduction of vulnerability of a given subject that is an object of risk assessment.

To ensure the subject security the subject assets governance must be established on the safety management that is proactive and it is based on project and process approaches that are concentrated to good handling with risks that are inherent to a given subject. If risks are not dealt correctly, so it is impossible to reach successfully targets, and therefore, the feasibility of procedures is reviewed in advance. The relevance of risk roles is caused by fact that the costs of project / process target implementation and the all successfulness depend on risk distribution. Therefore, it is necessary that each project may hold a special structure; risk distribution and financing that correspond to its character.

\subsection{Sources of risk}

The risks have different sources, i.e. they depend on the disasters, local vulnerabilities, methods of defeating and on response management and they originate on side of all participated stakeholders. To reach comprehension and following risk reduction it is necessary to perform its analysis that consists in the following phases:

1. Risk identification

2. Risk assessment

3. Risk allocation including the risk and the risk assignation to participated subjects

4. Risk treatment

5. Continuous monitoring and in case of need the application of corrective measures.

\subsection{Risk management process outputs}

The risk management model directs the subject to a continuous proactive risk management that leans on the promt identification, analysis, countermeasure planning, monitoring and governance of risks. Each risk passes through these steps at least once and often several times. In the first step there is determined the risk source, the character of possible failure, operational and commercial connections. In the second one there is determined the probability and impact (for calculation and mutual risk comparison). In the third one there are defined countermeasures leading to risk elimination, risk transfer to somebody else, negotiation with risk or its impact. In the fourth one there is obtained information on changes of individual risk elements in time. In the fifth one there are performed planning actions as reactions to appurtenant changes.

Outputs from risk management process for need of assets governance are the following: 
1. Risk assessment document - including the all information on appurtenant risk

2. Top risks list - including the list of selected risks the solution of which has the highest demands on sources and time

3. Retired risk list - serving as historical reference for future decision-making.

The safety management in comparison with the classic risk management uses the set of optimal measures against to all possible disasters respecting the physical nature of disasters possible in a given subject and it includes the precaution principle in concept promoted by the European Union at present (EU, 2000). Therefore, on the basis of present knowledge analysis, performed in work (Procházková (a), 2011), there is necessary for ensuring the security and sustainable subject development to change standard risk management to risk governance profiting the safety, called safety management. It is necessary to:

- establish synergic relations among the risks, vulnerability and safety

- model the process of decision-making the public administration with regard to risks and uncertainties (to perform support decision-making systems)

- specify legal conditions and protected measures

- improve activities of institutions (institutional changes).

Everyday facts and analyses of behaviour of both followed systems show that risks are going reality and that during the time new risks emerge. Therefore, it is necessary to live according to the concept of live with risks (US ISDR, 2005).

Reduction of each risk is connected with cost increase, with lack of knowledge, technical means etc. Therefore, in practice we search for boundary to which it is reasonable risk reduction in order that expended costs may be reasonable. This level of risk reduction (certain optimality) is mostly a subject of top management and of political decision-making, at which there are used the present scientific and technical findings and considered the economic, social and other conditions. The basic turn of subject management with regard to required targets is not possible to reach by individual partial measures but only by complex approach. To ensuring the security and sustainable development of subject there is necessary to use the co-ordinated and intentional approach. It enables step by step and in agreement with their importance and urgency to solve set of tasks in all domains and parts and by this to reach required subject state (Procházková (b), 2011).

\section{Real prevention and activities to mitigation risk}

As it was above said at the disaster occurrence there are originated chains of undesirable phenomena (impacts, consequences) of external and internal character, primary and secondary, which affect negatively the subject under consideration in different intensities and in different time moments. The substantial role plays the local vulnerability of subject and pertinent faults in human behaviour or management on all levels.

With regard to the historical development there are a lot of preventive and mitigation measures that are applied into practice by legal rules, technical standards and norms and public instructions. These ensure protection against to design basis disasters. In the case of beyond design disasters this protection does not exist and severe harms, damages and losses are caused not only by direct impacts on system 
safety but also through interdependencies arranged by couplings created in system by links and flows permanent or random character. These secondary impacts mostly affect the system assets and system security strongly and lengthy.

For both considered management types the land-use planning plays a big role because it ensures basic prevention against disasters of all kinds; i.e. natural, technological, environmental, social and caused by interdependencies in critical infrastructure, including terrorist attacks. In the frame of safety management there are performed measures in the land-use planning, designing, building and operation of objects and infrastructures. The measures are technical, low, organisational, economical etc. For this management type there is necessary (Procházková, 2007):

1. To consider all disasters that can occur in the subject under account (so called "All Hazard Approach" (FEMA, 1996))

2. At possible disasters there is necessary to take into account hazards of the $10^{\text {th }}$, $100^{\text {th }}$ and may be more year disasters

3. To carry out measures for vulnerability (and risks) reduction against disasters that can have unacceptable impacts on the subject assets

4. To carry out mitigation measures against unacceptable impacts on the assets, the occurrence of which cannot be prevented

5. To concentrate to critical assets, critical functions and critical activities which create the base for fulfilment of management aims in the subject

6. From the economical viewpoint it is necessary to implement only measures suitable for a given subject and effective not only in the limit time interval but in reasonable time period.

For realisation in practice there is necessary:

- formation (generation) of professional background for the decision making by the research and science support

- application of suitable management structure that will ensure the rational and qualified planning the measures

- building up and training the executive forces

- specialist training and systematic population education

- legal regulations, norms and standards

- inspections and other check mechanisms including the QA system

- special management types for emergency and critical cases.

From this it follows that a great role at creation of safe space there is played by level of management. As it was said above the subject management must be proactive, come out from sophisticated grounds, be tailored to real conditions and understandable to all subjects to which it is addressed. That it is necessary in order that the subject top management might recognise that the safety is not something in advance given, but that it must be created by conscious, directed and linked system measures and interventions, which from the theory viewpoint means to carry out management of safety (OECD, 2002). If we consider the emergency situation scale with degrees $0-5$ (Procházková (b), 2011), the subject safety management ensures:

- each human is capable to put under control the emergency situations of the 1 2 categories due to his/her education, training and preparation

- subject top management has the emergency management system for successful defeating the emergency situations of the 2 - 4 categories 
- subject top management has the crisis management system for successful defeating the emergency situations of the 5 category (i.e. the crisis).

In the frame of mentioned management systems the public administration and considered subject top managements and their administrative sections:

- build executive forces (fire-fighters, security guards, technical services, cyber safeguard etc.), that are prepared and trained for putting under control the emergency situations

- form financial and material resources in order to they may put under the control all possible emergency situations

- form the temporary systems which ensure the executive forces support under critical situations.

For ensuring the subject stability and its sustainable development there is necessary to ensure the continuity, i.e. the survival of emergency and critical till crisis situations (Disaster Advisors Inc, 2003). To this aim there is necessary to perform minimally the risk management and optimally the safety management.

The risk management is a planning, organisation, allocation of work tasks and check-up of resources of organisation so that there might be reduced losses, damages, harms, injuries or deaths caused by various disasters. The safety management consists in a planning, organisation, allocation of work tasks and check-up of sources of organisation with target to reach requested safety level. Its targets are higher than the risk management goals. It includes the principals that are important for sustainable development, i.e.:

- adequate expenses principle

- integration principle

- preliminary cautions (precaution) principle

- prevention principle

- synergy principle

- subsidiary (decentralisation) principle

- public space cultivation principle

- partnership principle

- exactness principle

- well-judged receiving the ecological and other liabilities principle.

\section{Groundwork for subject management}

With regard to the Czech (Procházková, 2007) and Slovak national project results (Králiková \& Badida, 2010) there is necessary for needs of safety management of a given subject to ensure qualified replies to the following questions:

1. What disasters can occur in a given subject and what impacts have they?

2. Where disasters can occur and how their impacts are spread in a given subject?

3. Under what conditions can disasters occur in a given subject and what conditions can cause escalation of their impacts?

4. How often can disasters occur in a given subject? 
5. From what disaster sizes have disasters in a given subject unacceptable impacts, that caused losses, harm and damages on assets?

6. What maximum sizes could reach disasters in a given subject?

7. What assets damages can be caused by maximum possible disaster on specified credibility level in a given subject and what are its impacts on a given subject?

8. What is possible to do in a given subject against unacceptable disaster impacts?

9. What are necessary measures against real disasters in a given subject in the technical, organisational, financial, social, legal, education and training domains?

10. What unacceptable and residual risks in the technical, organisational, financial, social, legal, education and training domains?

11. How does perform the response to disaster with aim to stabilize the subject state and to start renovation?

12. How does perform the renovation of subject and its assets with aim rationally to use resources, forces and means for the prohibition of further losses, the upgrade of resistance against possible disasters and for the start of further subject development with all items on which it is dependent?

13. What is suitable the form of management and of a given subject renovation and its assets performance after disaster and how is it possible to realise it?

14. How does create the financial / monetary reserve for rational renovation of a given subject and of its assets after disaster?

Then, for the subject safety management there is necessary with regard to hazard size and local vulnerability to divide known disasters into the following groups:

- disasters which cannot have impacts on a given subject

- disasters which have only acceptable impacts on a given subject, i.e. the relevant disasters

- disasters which have on a given subject only such impacts that might be put under the control at performance of preventive and mitigation measures, i.e. the specific disasters

- disasters which have on a given subject inadmissible impacts, and hence there is necessary to carry out the principal preventive measures the technical, organisational, legal and educational domains, i.e. the critical disasters which cause or can cause crisis situations.

The human system safety management of territory is based on these data, the environmental management system is so in-depth only in some cases - see www.epa.gov.ems/, www.inem.org (the environment impact assessment and strategic environment assessment are not so detailed).

\section{Procedure for Ensuring the Safety, Continuity and Sustainable Development of Subject}

With regard to results in works $[3,5,7,10-11,14]$ there is necessary for the subject safety ensuring to consider and to evaluate all disasters that have or can have unacceptable impacts on the subject, i.e. above all to determine disasters that have unacceptable risks which are impossible to avert by measures performed in advance and to split up them on: 
- specific, which may put under control by qualified and in-depth preparedness of response to these disasters using the standard forces, measures and resources,

- critical, which may put under control by standard and beyond standard forces, measures and resources including the limitation of the rights and freedoms of staff and citizens.

After this sorting there is necessary to specify and to apply measures for averting the disasters or their unacceptable impacts there, where it is possible, and there, where it is impossible to prepare in the frame of preparedness to response the measures for mitigation of unacceptable impacts.

The human system safety management of territory respects these facts (Procházková (b), 2011) and the environmental management system goes on so indepth only in some cases - see www.epa.gov.ems/, www.inem.org.

\section{Planning for Safety Management Needs}

Because there is a reality that it is impossible to avert some of unacceptable disaster impacts on assets being important and mostly requiring the investments, and because it is impossible to ward off by preventive measures, because they either do not exist or are not accessible financially, technologically or personally, therefore, there is necessary to perform emergency and crisis planning in a given subject.

The planning is consciously regulation of development. It is conscious activity of subject management that consists in the selection and presuming the aims, tasks, variants and ways, which condition the achievement of these aims. The most important feature of planning is the selection of aim. The planning is not the make-up of hierarchical commands file, which might be unthinkingly fulfilled, it is a creative activity, which must stipulate the real aim and determine the optimal way for its achievement. The planning is a fundamental section of each management. For achievement of the long-term aims there is used the strategic planning and for achievement the short-term aims objectives the operative planning; both have their particularities, which pre-determinate the selection of methods and ways.

The human, however, wants and must either precede critical situations or put under control the emergency, critical and crisis situations, and therefore, he / she must apply higher attention to the equation "insufficient awareness and insufficient understanding to crisis = insufficient preparedness, which means bad planning". Planning the measures, based on objective evaluation must be carried out during the land-use planning, designing, construction and operation, i.e. in the EU it is divided into ex ante, during and ex post.

In the planning domain there is necessary for determination, specification and realisation of preventive and mitigation measures in case of every relevant disaster to know the impact sizes and their distribution on the area. This groundwork must be prepared by pertinent research and scientific institutions, because they have data and needed knowledge to their interpretation. The role of decision making groundwork lastingly increase with the time, because also during intervention (response to disaster) there are the disaster characteristics that influence the commander decision making, e.g. the rate of disaster start (sudden or slow beginning), warning, 
preparation time, size of danger of, risks for participants of intervention, casualties, assessment, number of members of executive forces for intervention, stage of disaster development (beginning, period of secondary impacts etc.), main risks, used forces, number of commanders, required decision (routine, known, complex or unknown), sufficiency or insufficiency of material for intervention, knowledge of site, time of intervention, space location (one or more sites).

In the planning domain there is not still uniformity - most often there are used:

- security plan, the aim of which is to arrange subject needs and development,

- emergency plan, i.e. the set of response plans to emergency situations of the $3-4$ categories for foreseeable emergency situations,

- continuity plan,

- crisis plan, i.e. the set of response plans for putting under control the critical situations,

- contingency plan, i.e. the response plan for unforeseen situation.

The planning in subject, based on the stipulation of possible impacts and on costs, which a given subject will pay for failure, must be particularly taken to this assets and property that mostly require investments at renovation.

The human system safety management of territory respects these facts (Procházková (b), 2011) and the environmental management system respects these facts only in some cases - see www.epa.gov.ems/, www.inem.org (no obligatory realistic response plans to emergency and critical situations).

\section{Comparison of systems human safety and environmental management}

From the above given results there is clear that both followed management types, i.e. the human system safety management and the environmental management in the sense environment safety management are based on advanced risk management and that the human system safety management has more tool supporting safety (all hazard approach, procedure for disaster assessment, emergency plans, crisis plans). Logic comparison of basic items shows that considered management types differ by:

1. Assets, i.e.:

- environmental management has one asset "environment" and in advanced concept of the EU three pillars (environment, social, economic) (EU, 2000)

- human system safety management has several public assets and environment is only one of them .

2. Aims, i.e.:

- recent environmental management is aimed to secure environment with sustainable development enabling the human existence; the first is environment needs and the second human needs (www.epa.gov/ems), which does not enable to solve human needs in the sense of Maslow pyramid

- human system safety management is aimed to secure human system with sustainable development and it also takes care on environment but not as the main priority but as one of basic system assets, i.e. it has a chance to solve human needs in the sense of Maslow pyramid. 
Regarding these facts we can conclude that for humans the human system safety management is more acceptable because it has a chance to fulfil human needs in the sense of Maslow pyramid (www.inem.org). But the present problem is that we have not enough knowledge on interdependences among the human system assets that are sources of cross-section risks, on criteria and limits for negotiation with all types of risks existing in the human system. The aimed research is very necessary.

\section{Conclusion}

The security situation in the world, territory and organisation has been changing with the time, and therefore, there must be systematically built the safety culture, which taking into account actual piece of knowledge and experience. The safety culture promotion into practice requires both, the aimed management and broad participation of all staff of a subject under consideration with emphasising that the top management has the biggest responsibility. It understandably leads to the assignment of higher priority to planning and safety management as well as to higher demands to the understanding level of all participants.

Facts given above show that for effective management of all risks to both subjects considered, the environment and the territory represented by human system, there is necessary to apply in subject the sophisticated safety management. This represents integral, complex and system tool ensuring the subject safety and enabling its development. It acts in dynamically uncertain surroundings and systematically ensures the stability (prevention of crisis) and forms conditions for the next development. It leans on the monitoring, situation diagnostics, sophisticated analyses and processes appreciation, prediction of further process development, preventive and mitigation measures application before activities start and in their course, preparations of measures for correction of undesirable processes development or for putting under control the undesirable processes development and for ensuring the renovation etc. All partial tools are one another linked and sequenced by a way that leads to synergic effect.

The differences between the followed management types are in the priority aims: for environmental management the aim is to ensure secure environment with sustainable development enabling the human existence; and human system safety management is aimed to humans, however, it also respects the other assets among which is also the environment. If we stipulate that humans build the system for them, so we must agree that human system safety management inherently includes the environmental management by way that is more acceptable for humans. It means that we could not create too many management types in practice but to create only one which will build world for humans on correct base.

\section{Acknowledgements}

The paper presents results of research in the frame of national grant No 382019TUKE-4/2010 Environmental measuring and monitoring in mechanical engineering plants. 
Prochazkova, D.; Wessely, E.; Rusko, M. \& Kralikova, R.: Human System Safety...

\section{References}

Disaster Advisors Inc.: Bussiness Continuity Planning. 2003. http://www.disasteradvisors.com/ disasterplanning.htm

Estokova, A. (2008) : Environmental certification of building materials in Slovak republic. In: Visnik Nacional'nogo universitetu L'vivska politechnika. No. 627 (2008), p. 219-222. - ISSN 0321-0499

EU: European Commission Adopts Communication on Precautionary Principle. Brussels 2000. http://europa. eu.int/ rapid/press

EU: Risk Assessment and Mapping Guidelines for Disaster Management. Working paper SEC(2010) 1626. Brussels 2010

FEMA: Guide for All-Hazard Emergency Operations Planning. State and Local Guide (SLG) 101. FEMA, Washinton 1996

ISO (2008): Draft International Standard ISO/DIS 31000, Risk management Principles and guidelines on implementation, 2008, $18 \mathrm{p}$

Králiková, R.- Miháliková, R.: (2009) Product life cycle management applications, In: RIM 2009 : development and modernization of production : 7th international scientific conference : Cairo, Egypt, p. 207-208. - ISBN 9789958-624-29-2

Králiková, R. , Badida,M. (2010): Environmental measuring and monitoring in mechanical engineering plants. Kosice, 150 pp, ISBN 978-78-80-0464-9

OECD: Guidance on Safety Performance Indicators. Guidance for Industry, Public Authorities and Communities for developing SPI Programmes related to Chemical Accident Prevention, Preparedness and Response. OECD, Paris 2002, 191pp

OECD: Assessing Societal Risks and Vulnerabilities. OECD Studies in Risk Management, Denmark. Paris, 2006

Procházková D.: Methodology for Estimation of Costs for Renovation of Property in Territories Affected by Natural or Other Disaster (in Czech). SPBI SPEKTRUM XI Ostrava 2007, ISBN 978-80-86634-98-2, 251p

Procházková D.: Risk Analysis and Risk Management (in Czech). Grada, Praha 2011, in print, $400 \mathrm{p}$

Procházková D.: Strategic Management of Safety of Territory and Organisation (in Czech). Grada, Praha 2011, in print, 399p

Raven, P. H.- Berg, L. R. Johnson G. B.: Environment. ISBN 003018679X, 9780030186790. Saunders College Pub., 1998, 579p

UN: Human Development Report. New York 1994, www.un.org

US ISDR: World Conference on Disaster Reduction Declaration. Kobe 2005, 25p., Www.un.org

US Project Management Institute, A Guide to the Project Management Body of Knowledge. US Project Management Institute, Washington 2004

Wessely, E. - Kralikova, R. - Krupa, M. (2008): Efficient management in production companies by implementation of PLM, In: Annals of DAAAM for 2008 \& proceedings of the 19th International DAAAM Symposium. - Vienna : DAAAM International, p. 1527-1528. - ISBN 9783901509681

*** (2011) Www.epa.gov/ems

*** (2011) WWW.inem.org 